\title{
Comparative Photovoltaic Study of Physical Blending of Two Donor- Acceptor Polymers with the Chemical Blending of the Respective Moieties
}

\author{
Qianqian Zhang, ${ }^{\dagger, \perp}$ Mary Allison Kelly, ${ }^{\dagger, \perp}$ Adrian Hunt, ${ }^{\S}$ Harald Ade, ${ }^{\S}$ and Wei You*, ${ }^{\dagger}$ \\ ${ }^{\dagger}$ Department of Chemistry, University of North Carolina at Chapel Hill, Chapel Hill, North Carolina 27599-3290, United States \\ ${ }^{\S}$ Department of Physics, North Carolina State University, Raleigh, North Carolina 27695, United States
}

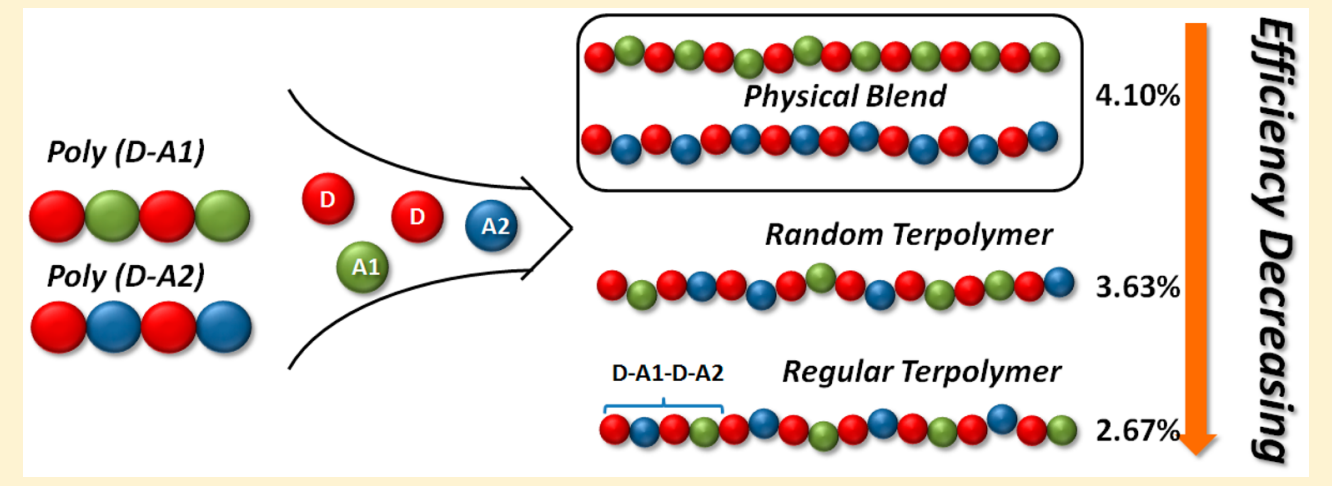

ABSTRACT: A regularly alternating terpolymer and a random terpolymer were synthesized from the constituent units of two donor-acceptor polymers with complementary absorption. They were then compared to a physical blend of these two donoracceptor polymers in order to investigate the best means of extending the light absorption range in bulk heterojunction (BHJ) solar cells. While all three methods broadened the light absorption, the physical blend provided the best improvement in power conversion efficiency ( $4.10 \%$ vs $3.63 \%$ and $2.67 \%$ for the random and regular terpolymers, respectively). This is due to the increase in aggregation in the physical blend, as demonstrated in the UV-vis spectra, which likely leads to higher local mobility and less recombination. This study shows that in order to effectively increase the light absorption (and therefore performance) of a polymer:fullerene based $\mathrm{BHJ}$ solar cell, a terpolymer must retain a structure which allows sufficient aggregation.

\section{INTRODUCTION}

In a typical bulk heterojunction $(\mathrm{BHJ})$ polymer solar cell (PSC), the conjugated polymer functions as the major light absorber while the electron accepting material-most often a fullerene derivative-absorbs very little sunlight. Unfortunately, the inherently narrow absorption range of typical conjugated polymers, usually with a full width at half-maximum (fwhm) on the order of $200 \mathrm{~nm}$, only covers a relatively small fraction of the solar spectrum. ${ }^{1}$ This significantly limits the light absorption and thus the short circuit current $\left(J_{\mathrm{sc}}\right)$ of these PSCs. The "engineering" approach to address this issue of light absorption is to stack several solar cells with each of them capturing a different region of the solar spectrum; these cells are then connected in a series or parallel circuit (i.e., tandem cells). ${ }^{2-4}$ Though such tandem cells can maximize the light absorption and utilize it well (e.g., overcoming the thermalization loss) with much higher projected efficiency, ${ }^{4}$ the complex device configuration of these tandem cells has posed serious challenges in terms of fabrication and optimization. On the other hand, within the realm of single junction $\mathrm{BHJ}$ solar cells, various strategies have been explored to improve the light absorption and (hopefully) further improve the efficiency of PSCs. Explored strategies include, (a) adopting more lightabsorbing $\mathrm{C}_{70}$ derivatives, ${ }^{5}$ (b) using multiple polymers covering different absorption ranges in the same active layer as a physical blend (e.g., ternary blend systems), ${ }^{6-9}$ (c) covalently integrating these conjugated polymers together (e.g., chemically blending these constituting monomers into a random copolymer), ${ }^{10}$ (d) replacing the fullerenes with strongly light-absorbing electron-accepting molecules, ${ }^{11}$ and (e) compensating weak absorption by using thick layers. ${ }^{12,13}$

While the strategy of replacing $\mathrm{C}_{60}$ derivatives (e.g., $[6,6]$ phenyl- $\mathrm{C}_{61}$-butyric acid methyl ester $\left.\left(\mathrm{PC}_{61} \mathrm{BM}\right)\right)$ with light absorbing $\mathrm{C}_{70}$ counterparts (e.g., [6,6]-phenyl- $\mathrm{C}_{71}$-butyric acid methyl ester $\left(\mathrm{PC}_{71} \mathrm{BM}\right)$ ) has been quite successful (in fact, almost all reported record-high efficiencies of polymer solar cells were obtained with $\mathrm{PC}_{71} \mathrm{BM}$ in the $\mathrm{BHJ}$ blend), other strategies have only seen success in some cases. For example,

Received: November 29, 2015

Revised: $\quad$ March 7, 2016

Published: March 22, 2016 
Scheme 1. Synthesis of Four Polymers Used in This Study, PBnDT-DTBT, PBnDT-HTAZ, Poly(BnDT-DTBT/HTAZ), and Poly(BnDT-HTAZ-alt-BnDT-DTBT)

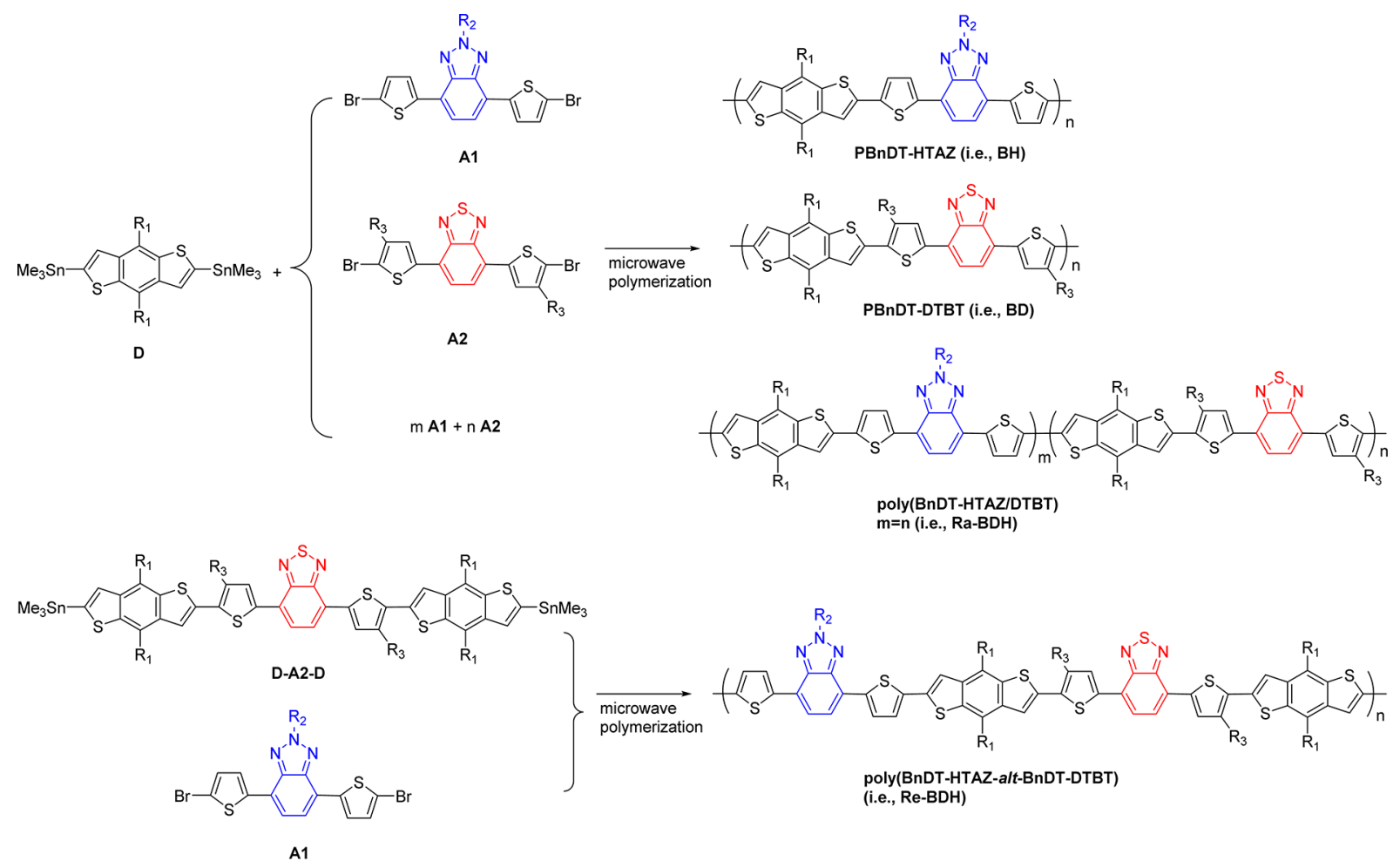

a) $R_{1}=3$-butylnonyl, $R_{2}=2$-butyloctyl, $R_{3}=2$-ethylhexyl

b) microwave polymerization: $\mathrm{Pd}_{2}(\mathrm{dba})_{3} \cdot \mathrm{CHCl}_{3}, \mathrm{P}(\mathrm{o} \text {-tolyl })_{3}$, o-xylene, microwave heating

ternary (or multiple) blend systems, where two (or more) polymers or fullerene derivatives are physically mixed in a single layer, have gained significant momentum, achieving efficiencies over $8 \%{ }^{9,14-16}$ However, "non-working" ternary blends were also reported together with working ternary blends, ${ }^{14,17,18}$ highlighting the complex nature of these systems. It appears that matching the morphology or texture (e.g., both polymers being "face-on" with the same processing solvent) is an important factor. ${ }^{14}$ On the other hand, terpolymers, where three different units from two parent donor:acceptor polymers are strategically combined to provide chemical blending and thus integrate the electronic and absorption features of both parent polymers, can potentially circumvent the morphology compatibility requirements of a ternary physical blend. This is because the active layer only contains two components (i.e., a terpolymer and a fullerene derivative) as in a typical binary $\mathrm{BHJ}$ solar cell.

Indeed, a number of terpolymers have been developed in the past few years, typically through a random copolymerization of several different electron-donating units ("donor", D) and electron-deficient units ("acceptor", A). ${ }^{19-23}$ However, the nature of such random copolymerizations implies that the structure and composition of these random terpolymers are not well-defined compared to the prevailing one donor-one acceptor copolymers. One approach to address this "randomness" is to construct a macro-monomer that places the constituent donors/acceptors in the desired pattern, before it is subjected to the final polymerization (with another donor or acceptor). ${ }^{24-28}$ Though synthetically more demanding, such a regular terpolymer has the potential to reach higher efficiency than the corresponding random terpolymer. ${ }^{26,27,29}$ The welldefined conjugated structure of the regular terpolymer would more likely lead to favorable device morphology compared to the unregulated structure of the random copolymer. For example, the likely existence of oligomeric segments with a different chemical and electronic/optical nature in a random copolymer could lead to poor mixing with the fullerene derivatives as well as poor molecular packing and orientation in the $\mathrm{BHJ}$ active layer. ${ }^{26,27,29,30}$

In principle, any two $p$-type conjugated polymers can form a ternary blend (i.e., physical blend) with an $n$-type fullerene derivative. Alternatively, the constituent units (i.e., structural moieties) of two such polymers-if they have a common structural moiety-can also be organized into a random terpolymer or a regular terpolymer, both of which can be considered chemical blends. As briefly discussed above, all three approaches have been successfully implemented with different systems; however, for any two given conjugated polymers, it is essentially impossible to predict which approach would offer the highest device efficiency unless one investigates all three approaches in a comparative manner. Unfortunately, such studies are very rare, ${ }^{26,31}$ and the results are mixed. In one study, Sun et al. reported that an alternating D-A1-D-A2 copolymer containing two acceptors (A1 and A2) in the repeat unit (i.e., a regular terpolymer) showed a broad absorption and much higher device efficiency (5.03\%) than that of the corresponding physical blend $(2.40 \%) .^{26}$ In another study, Khlyabich et al. obtained similar efficiencies for both the ternary blend and the random terpolymer for another pair of parent polymers. $^{31}$ More such comparative studies are therefore 
Scheme 2. Synthesis of Monomer D-A2-D

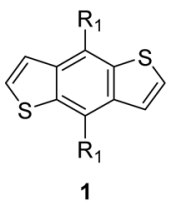

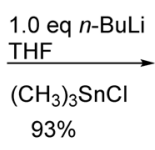

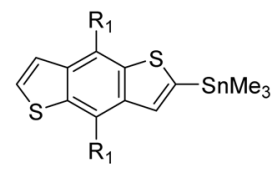

2

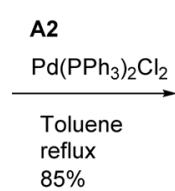

$85 \%$

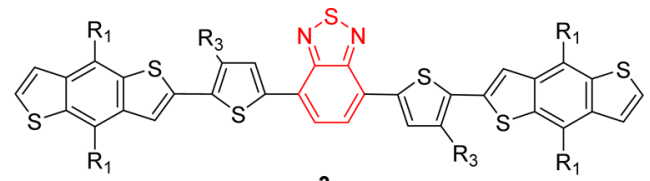

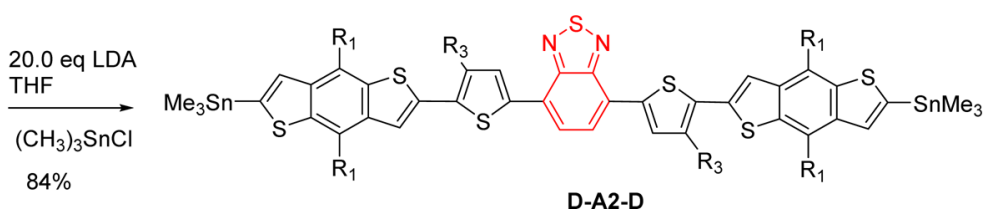

needed to further explore the application and limitations of all three approaches (i.e., ternary blend, random copolymer and regular terpolymer).

We designed this comparative study by starting with a successful ternary blend we reported earlier, poly(benzodithiophene-dithienylbenzotriazole) (PBnDT-HTAZ) and poly(benzodithiophene-dithienylbenzothiadiazole) (PBnDT-DTBT). ${ }^{32}$ These two polymers share a common donor (i.e., " $\mathrm{D}$ " being benzodithiophene), but differ in the acceptors (i.e., "A1" being HTAZ, and “A2" being DTBT). For this comparative study, two new terpolymers were synthesized: a random copolymer poly $(\mathrm{BnDT}-\mathrm{HTAZ} / \mathrm{DTBT})$ and a regular, alternating terpolymer poly $(\mathrm{BnDT}-\mathrm{HTAZ}$-altBnDT-DTBT) (Scheme 1). The three different approaches to organizing these constituent units (ternary physical blend, random terpolymer, and regular terpolymer) give different absorption behavior, though all show a broadened absorption. However, while the ternary blend (i.e., PBnDTDTBT:PBnDT-HTAZ:PC ${ }_{61} \mathrm{BM}$ ) shows a higher energy conversion efficiency $(4.1 \%)$ than either parent binary blend (PBnDT-DTBT:PC ${ }_{61} \mathrm{BM}$, or PBnDT-HTAZ:PC ${ }_{61} \mathrm{BM}$ ), as previously reported, ${ }^{32}$ the two terpolymer based solar cells exhibit lower efficiency at similar active layer thicknesses $(\sim 110$ $\mathrm{nm})$. This is due to noticeably lower short circuit currents $\left(J_{\mathrm{sc}}\right)$ of these two terpolymer base devices than that of the ternary blend based device. In fact, the $J_{\mathrm{sc}}$ of the regular alternating terpolymer based device is the lowest among all devices tested; we ascribe this to a decrease in absorbance efficiency of the active layer due to reduced aggregation of the regular terpolymer, less than optimal morphology of the active layer, and likely electronic differences of the regular terpolymer compared to the parent polymers. Our results indicate that while the ternary blend is an effective approach to extend the absorption with improved device efficiency in our series of blends, the regular terpolymer is, rather surprisingly, not. Together with previous reports, ${ }^{26,31}$ our comparative study highlights the complexity inherent in the design of novel polymers for higher efficiency solar cells.

\section{RESULTS AND DISCUSSION}

Synthesis. The chemical structures and synthesis of all four polymers used in this study are presented in Scheme 1. For clarity and simplicity, we will use $\mathrm{BD}, \mathrm{BH}, \mathrm{Ra}-\mathrm{BDH}$, and $\mathrm{Re}-$ $\mathrm{BDH}$ to represent $\mathrm{PBnDT}-\mathrm{DTBT}, \mathrm{PBnDT}-\mathrm{HTAZ}$, the random terpolymer (i.e., poly(BnDT-HTAZ/DTBT)), and the regular terpolymer (i.e., poly $(\mathrm{BnDT}-\mathrm{HTAZ}$-alt-BnDT$\mathrm{DTBT})$ ). Thus, the ternary blend will be referred to as $\mathrm{BD}: \mathrm{BH}$. Monomers $\mathrm{D},{ }^{33} \mathrm{Al}^{13}$ and $\mathrm{A} 2^{34}$ were readily prepared according to previous reports, and were then employed to create three polymers (BH, BD, and $\mathrm{Ra}-\mathrm{BDH}$ in Scheme 1). We used 1:1 feed ratio of $\mathrm{A} 1: \mathrm{A} 2$ in the synthesis of $\mathrm{Ra}-\mathrm{BDH}$ for this comparative study. The actual ratio of $\mathrm{A} 1: \mathrm{A} 2$ on the $\mathrm{Ra}-\mathrm{BDH}$ was close to $1: 1$, as confirmed by the high temperature NMR (Figure S6) and elemental analysis (Table S1).

However, the synthesis of the regular, alternating polymer (i.e., $\mathrm{Re}-\mathrm{BDH}$ in Scheme 1) was only made possible after extensive exploration and optimization of reaction conditions. The key to synthesizing the $\mathrm{Re}-\mathrm{BDH}$ was the preparation of the D-A2-D structure in Scheme 1. First, monostannylated $\operatorname{BnDT}(2)$ was prepared by treating $\operatorname{BnDT}$ (1) with 1 eq $n$ $\mathrm{BuLi}$ (Scheme 2), and the crude product (without further purification) was directly subjected to the Stille coupling with dibrominated monomer A2 to afford the premonomer (3). The final step in synthesizing the polymerizable monomer, D-A2$\mathrm{D}$, was the stannylation of premonomer (3) assisted by a strong base. Interestingly, when $n$-BuLi was employed, none of the desired product was obtained. Furthermore, treating premonomer (3) with stoichiometric amount of LDA (or slight excess) did not lead to the desired monomer, either. In fact, we discovered that 20 equiv of LDA (vs 3 ) at low temperature was required to successfully convert the premonomer (3) to the polymerizable monomer $\mathrm{D}-\mathrm{A} 2-\mathrm{D}$. Less than 20 equiv of LDA gave a significant amount of monostannylaed monomer, which was difficult to separate from the distannylated product. Finally, the monomer $\mathrm{D}-\mathrm{A} 2-\mathrm{D}$ was combined with monomer $\mathrm{A} 1$ via the standard microwave Stille polymerization to create the regular terpolymer (i.e., $\mathrm{Re}-\mathrm{BDH}$ in Scheme 1).

The number-averaged molecular weights $\left(M_{\mathrm{n}}\right)$ of $\mathrm{BD}, \mathrm{BH}$, $\mathrm{Ra}-\mathrm{BDH}$, and $\mathrm{Re}-\mathrm{BDH}$ were determined to be $54,80,66$, and $39 \mathrm{~kg} / \mathrm{mol}$, with corresponding dispersity $(\boxplus)$ of $2.13,1.91$, 2.55, and 3.46, respectively (Table 1).

Optical and Electrochemical Properties. The UV-vis absorption spectra of the four polymers in solution (odichlorobenzene, oDCB, was used as the solvent) and as thin

Table 1. Molecular Weight, Photophysical, And Electrochemical Properties of the Four Polymers

$\begin{array}{lcccccc}\text { polymer } & \begin{array}{c}M_{\mathrm{n}} \\ (\mathrm{kg} / \mathrm{mol})\end{array} & \begin{array}{c}\text { dispersity } \\ (Ð)\end{array} & \begin{array}{c}\lambda_{\max }^{\text {film }} \\ (\mathrm{nm})\end{array} & \begin{array}{c}\lambda_{\max }^{\text {sol }} \\ (\mathrm{nm})\end{array} & \begin{array}{c}E_{\mathrm{g}}^{\text {opt }} \\ (\mathrm{eV})^{a}\end{array} & \begin{array}{c}E_{\mathrm{HOMO}} \\ (\mathrm{eV})^{b}\end{array} \\ \mathrm{BD} & 54 & 2.13 & 702 & 563 & 1.65 & -5.28 \\ \mathrm{BH} & 80 & 1.91 & 582 & 573 & 1.96 & -5.30 \\ \mathrm{Ra}-\mathrm{BDH} & 66 & 2.55 & 579 & 561 & 1.70 & -5.39 \\ \mathrm{Re}-\mathrm{BDH} & 39 & 3.46 & 581 & 536 & 1.76 & -5.29\end{array}$

${ }^{a}$ Calculated from the onset of UV-vis absorption spectra of polymer films. ${ }^{b}$ Measured by cyclic voltammetry. 

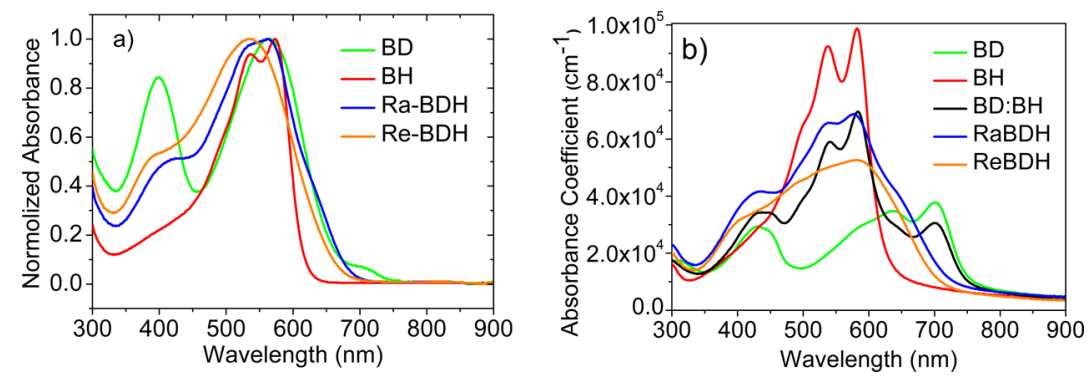

Figure 1. UV-vis absorption spectra of four polymers in ortho-dichlorobenzene (o-DCB) solution (a) and films (including the ternary blend) spun cast from o-DCB solution (b).

films are shown in Figure 1, parts a and b, respectively. Figure $1 \mathrm{~b}$ also includes the absorption of the 1:1 (weight ratio) blend of $\mathrm{BD}: \mathrm{BH}$. In solution, both terpolymers $(\mathrm{Ra}-\mathrm{BDH}$ and $\mathrm{Re}-$ $\mathrm{BDH})$ show very similar absorption features, with increased absorption width compared to either of the parent polymers (BD or $\mathrm{BH}$ ). However, the thin film absorption of these two terpolymers is distinctively different, particularly at longer wavelengths. The characteristic absorption peaks from these two parent polymers, $430 \mathrm{~nm}$ for $\mathrm{BD}$ and 535 and $575 \mathrm{~nm}$ for $\mathrm{BH}$, are clearly visible in the random terpolymer $(\mathrm{Ra}-\mathrm{BDH})$. In contrast, the absorption spectrum of the regular terpolymer $(\mathrm{Re}-\mathrm{BDH})$ is almost featureless from 350 to $700 \mathrm{~nm}$. This difference in the thin film absorption between $\mathrm{Ra}-\mathrm{BDH}$ and $\mathrm{Re}-\mathrm{BDH}$ suggests that there exist oligomeric segments of $(\mathrm{BnDT}-\mathrm{DTBT})_{x}$ and $(\mathrm{BnDT}-\mathrm{HTAZ})_{y}$ that can aggregate in the random terpolymer, due to the random nature of the synthesis of $\mathrm{Ra}-\mathrm{BDH}$; while the regular, alternating nature of $\mathrm{Re}-\mathrm{BDH}$ implies that there are no such oligomeric segments present in its structure. The aggregation of BD units (700-750 $\mathrm{nm})$ is particularly suppressed and disrupted in both terpolymers, whereas the aggregation of the $\mathrm{BH}$ is partially present in the random terpolymer, but completely lacking the characteristic vibrational features in the regular terpolymer. On the other hand, the ternary blend ( $\mathrm{BD}: \mathrm{BH}$ at $1: 1$ weight ratio) covers the whole absorption range of the two parent polymers and captures corresponding absorption features including the signature for aggregation from both the two parent polymers. Finally, from the onset absorption of the thin film (Figure $1 \mathrm{~b}$ ), the band gaps of all studied polymers were calculated and the data are summarized in Table 1 .

The electrochemical properties of the four polymers were evaluated via cyclic voltammetry (CV) (Figure 2). From the oxidation onset potentials of these polymers (vs ferrocene/ ferrocenium, $\mathrm{Fc} / \mathrm{Fc}+$ ), we estimated the highest occupied molecular orbital (HOMO) energy levels according to the equation $E_{\mathrm{HOMO}}=-e\left(E_{\mathrm{OX}}+4.80 \mathrm{~V}\right)$, with data included in Table 1 . It is interesting to note that the calculated HOMO

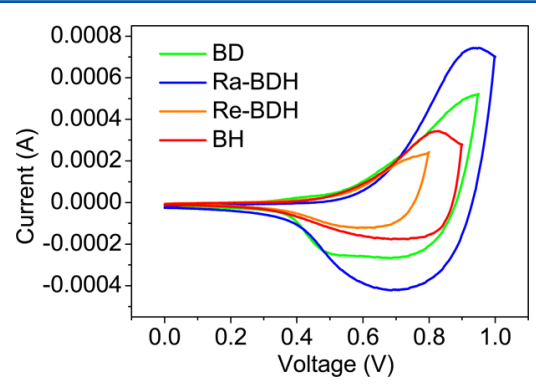

Figure 2. Cyclic voltammetry oxidation curves of the four polymers. level of $\mathrm{Ra}-\mathrm{BDH}$ appears to be $\sim 0.1 \mathrm{eV}$ lower than those of other three polymers (though we believe this slight difference is within the experimental error, given the estimative nature of CV).

Photovoltaic Properties. The photovoltaic properties of all four polymers were measured by fabricating solar cells with a configuration of ITO/PEDOT:PSS/polymer:PC ${ }_{61} \mathrm{BM} / \mathrm{Ca} / \mathrm{Al}$. In order to establish a meaningful comparison of the photovoltaic properties of all five polymers (including the ternary blend), we applied identical fabrication conditions for all five active layers as published previously, including the processing solvent (ortho-dichlorobenzene, o-DCB), ratio of polymer: $\mathrm{PC}_{61} \mathrm{BM}(1: 1 \mathrm{wt})$, and the solvent annealing time (12 h). ${ }^{32}$ Furthermore, the thicknesses of all five active layers were maintained at $\sim 110 \mathrm{~nm}$, in order to eliminate any thickness induced effect on the device performance (e.g., $J_{\text {sc }}$ ), which could complicate the data interpretation and comparison.

All characteristic photovoltaic properties are summarized in Table 2, with representative $J-V$ curves shown in Figure 3 a. First of note, the open circuit voltage $\left(V_{\mathrm{oc}}\right)$ of the ternary blend $(\mathrm{BD}: \mathrm{BH})$ based solar cell is between those of the two parent polymer (BD or $\mathrm{BH})$ based devices, which agrees well with our previous study. ${ }^{32}$ Interestingly, the $V_{\text {oc }}$ values of the two terpolymer $(\mathrm{Re}-\mathrm{BDH}$ and $\mathrm{Ra}-\mathrm{BDH})$ based solar devices are slightly higher than the higher $V_{\text {oc }}$ of the two parent polymer based devices. This enhanced $V_{o c}$, observed for both terpolymers, is worth noting, because most other terpolymers reported showed $V_{\text {oc }}$ values in between the $V_{\text {oc }}$ values of the two parent polymers. ${ }^{19,26}$ The much higher $V_{\text {oc }}$ values of these ternary polymers in this study, in particular compared to the low $V_{\text {oc }}$ of the ternary blend, demonstrate that it is possible to maintain a high $V_{\text {oc }}$ with the terpolymer approach, a clear advantage over the ternary blend approach. But as will be shown, this increased $V_{\text {oc }}$ is not significant enough to enhance the overall efficiency.

The $J_{s c}$ values of the two terpolymer based devices, in particular that of the regular terpolymer $(\mathrm{Re}-\mathrm{BDH})$, are much smaller than either of the parent polymer based cells. The ternary blend, on the other hand, shows the highest $J_{\text {sc }}$ in this series of devices. It appears that chemical blending (i.e., $\mathrm{Re}-$ $\mathrm{BDH}$ and $\mathrm{Ra}-\mathrm{BDH}$ ) in the studied series of polymers is not a viable approach to improving the $J_{\text {sc }}$ compared to the physical blend (i.e., BD:BH). However, all three blends ( $\mathrm{Re}-\mathrm{BDH}, \mathrm{Ra}-$ $\mathrm{BDH}$, and $\mathrm{BD}: \mathrm{BH}$ ) show improved absorption width with respect to either of the parent polymers (BD or $\mathrm{BH}$ ) (Figure 1b). Measurement of the external quantum efficiency (EQE) confirms the observed difference on the $J_{\mathrm{sc}}$ of all devices (Figure $3 b)$. In order to ascertain whether the lower current generation stemmed from a difference in absorption coefficients for the two terpolymers, the optical spectra of the devices were 
Table 2. Photovoltaic Properties and Hole Mobilities of the Four Polymers and Physical Blend of PBnDT-DTBT and PBnDT-HTAZ in their BHJ Devices with $\mathrm{PC}_{61} \mathrm{BM}$

\begin{tabular}{|c|c|c|c|c|c|c|c|c|}
\hline polymer: $\mathrm{PC}_{61} \mathrm{BM} \mathrm{BHJ}$ & hole mobility $\left[\times 10^{-4} \mathrm{~cm}^{2} /(\mathrm{V} \cdot \mathrm{S})\right]$ & $\begin{array}{l}\text { thickness } \\
(\mathrm{nm})\end{array}$ & $J_{\mathrm{sc}}\left(\mathrm{mA} / \mathrm{cm}^{2}\right)$ & $V_{\mathrm{oc}}(\mathrm{V})$ & $\begin{array}{l}\text { fill factor } \\
(\%)\end{array}$ & $\begin{array}{c}\mathrm{PCE} \\
\left(\mathrm{mW} / \mathrm{cm}^{2}\right)\end{array}$ & $\begin{array}{c}J_{\mathrm{abs}} \\
\left(\mathrm{mA} / \mathrm{cm}^{2}\right)\end{array}$ & $J_{\mathrm{sc}} / J_{\mathrm{abs}}$ \\
\hline $\mathrm{BD}$ & $2.25 \pm 0.77$ & $138 \pm 2$ & $9.22 \pm 0.28$ & $0.813 \pm 0.003$ & $52.4 \pm 0.5$ & $3.93 \pm 0.12$ & 10.84 & 0.85 \\
\hline $\mathrm{BH}$ & $0.93 \pm 0.4$ & $115 \pm 7$ & $7.63 \pm 0.37$ & $0.690 \pm 0.002$ & $58.7 \pm 0.9$ & $3.09 \pm 0.17$ & 8.98 & 0.85 \\
\hline BD:BH & $1.97 \pm 0.55$ & $112 \pm 14$ & $9.36 \pm 0.46$ & $0.770 \pm 0.005$ & $56.9 \pm 1.1$ & $4.10 \pm 0.29$ & 10.47 & 0.89 \\
\hline $\mathrm{Ra}-\mathrm{BDH}$ & $1.36 \pm 0.46$ & $108 \pm 14$ & $6.55 \pm 0.31$ & $0.853 \pm 0.003$ & $64.9 \pm 1.7$ & $3.63 \pm 0.21$ & 9.02 & 0.73 \\
\hline $\mathrm{Re}-\mathrm{BDH}$ & $0.85 \pm 0.24$ & $111 \pm 17$ & $5.57 \pm 0.25$ & $0.838 \pm 0.006$ & $57.3 \pm 2.3$ & $2.67 \pm 0.13$ & 7.88 & 0.71 \\
\hline
\end{tabular}
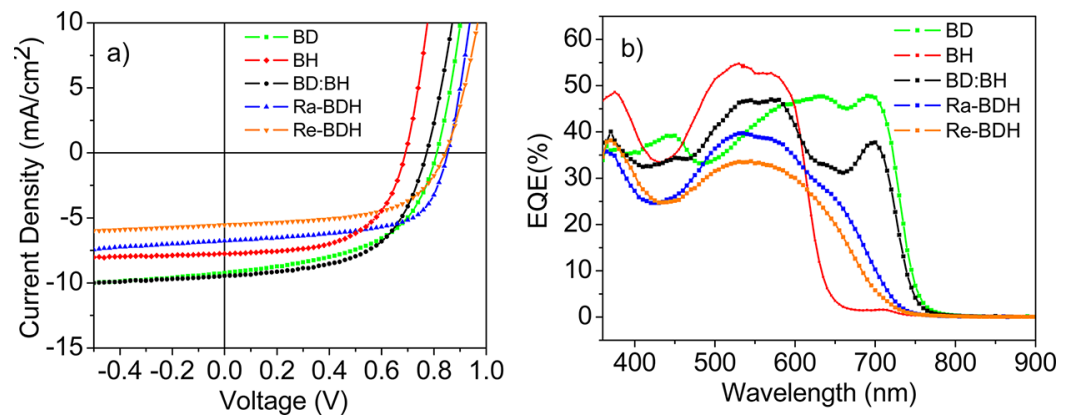

Figure 3. Representative $J-V$ curves (a) and related EQE (b) for all devices.

integrated to yield a theoretical expected current assuming $100 \%$ IQE. This procedure (see Supporting Information) yields the values listed in Table $2\left(J_{\mathrm{abs}}\right)$. Dividing the measured $J_{\mathrm{sc}}$ by the absorbance corrected current, $J_{\mathrm{abs}}$, leads to a normalized current $\left(J_{\mathrm{sc}} / J_{\mathrm{abs}}\right)$ which can be compared across all blends. The normalized currents cluster into two categories: the parent polymers and the physical blend $(0.85,0.85$, and 0.89$)$ and the terpolymers or chemical blend approach ( 0.73 and 0.71$)$. Thus, the improved $J_{\mathrm{sc}}$ for the physical blend, is in large part due to improved absorption (since normalized currents are similar for both parent polymers and the physical blend). However, the differences in absorption cannot completely account for the different in $J_{s c}$ between the physical and chemical blends. Rather, although $\mathrm{Ra}-\mathrm{BDH}$ has higher absorption coefficient than the physical blend (Figure 1b), the physical blend does a better job of generating and collecting charges (as evidenced by the higher normalized current). We also measured the long distance device hole mobility of all five blends, which are all on the order of $10^{-4} \mathrm{~cm}^{2} /(\mathrm{V} \cdot \mathrm{s}$ ) (Table 2); apparently, the longrange device hole mobility cannot completely account for the observed difference in $J_{\mathrm{sc}}$ between the two terpolymers and the ternary blend, especially given such thin films $(\sim 100 \mathrm{~nm})$. The observed difference in $J_{\text {sc }}$ between the chemical blends and the other devices may also be related to the morphology or intrinsic charge generation efficiencies and geminate recombination.

Morphology Study. To further understand the differences between $\mathrm{Ra}-\mathrm{BDH}, \mathrm{Re}-\mathrm{BDH}$, and the physical blend based solar cells compared to the parent binary based solar cells, we utilized a set of X-ray techniques to study the morphology and molecular packing of these polymer:fullerene blends.

Resonant soft X-ray scattering (R-SoXS), measured at beamline 11.0.1.1 at the Advanced Light Source, ${ }^{35}$ provided information on the domain spacing and domain purity of the system. R-SoXS images were measured at $282.4 \mathrm{eV}$ to provide good material contrast, while avoiding fluorescence. The images were processed using a modified form of the Nika software package $^{36}$ implemented within Igor; details on the measurement and analysis methodology can be found in the Supporting Information. For all displayed R-SoXS sector averages (Figure
4), the recorded intensity was Lorentz-corrected by multiplying each curve by $\mathrm{q}^{2}$, as is appropriate for the assumed 3-

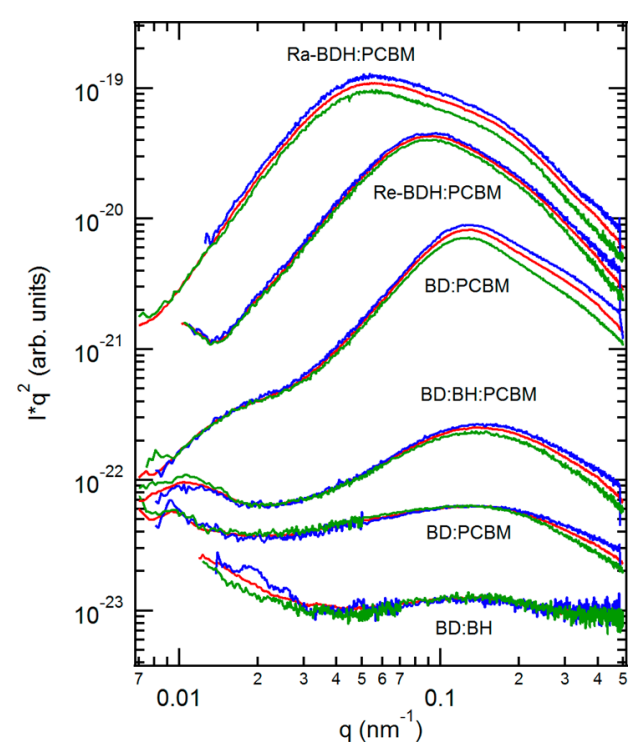

Figure 4. R-SoXS measurements and analysis. For each sample, the calculated vertical sector average (blue), horizontal sector average (green), and full circular average from the RSoXS images are shown. Note that the ordinate axis is logarithmic, so the curves have been given an offset via a multiplicative constant.

dimensional structures dominated by structure factor, rather than form factor. ${ }^{37}$ Most R-SoXS profiles and their anisotropy differences (Figure 4) clearly show signatures of multiple peaks, and as such, the vertical and horizontal sectors for each sample were fit with the minimum number of peaks needed. Two lognormal distributions were required to reproduce the sector averages of all samples. These distributions sometimes had similar modes, but different widths and thus different medians and were necessary for good fits even in cases where the profiles did not show any obvious sign of two features (see Supporting Information for details). Table 3 summarizes the 
Table 3. Morphological Parameters for All Samples

\begin{tabular}{|c|c|c|c|c|}
\hline polymer: $\mathrm{PC}_{61} \mathrm{BM} \mathrm{BHJ}$ & $\begin{array}{l}\text { median domain spacing } \\
\text { (high- } q \text { peak })[\mathrm{nm}]\end{array}$ & $\begin{array}{l}\text { relative scattering intensity } \\
\text { (high- } q \text { peak) }\end{array}$ & $\begin{array}{l}\text { median domain spacing } \\
\quad(\text { low- } q \text { peak })[\mathrm{nm}]\end{array}$ & $\begin{array}{l}\text { relative scattering intensity } \\
\text { (low- } q \text { peak) }\end{array}$ \\
\hline $\mathrm{BD}$ & $20.2 \pm 2.0$ & $0.68 \pm 0.12$ & $243 \pm 36$ & $0.84 \pm 0.14$ \\
\hline $\mathrm{BH}$ & $24.0 \pm 2.4$ & $0.83 \pm 0.08$ & $47.0 \pm 2.4$ & $1.15 \pm 0.10$ \\
\hline BD:BH & $25.1 \pm 2.5$ & $0.74 \pm 0.12$ & $328 \pm 49$ & $0.39 \pm 0.03$ \\
\hline $\mathrm{Ra}-\mathrm{BDH}$ & $44.7 \pm 4.5$ & $1.00 \pm 0.12$ & $116.3 \pm 5.8$ & $1.00 \pm 0.11$ \\
\hline $\mathrm{Re}-\mathrm{BDH}$ & $38.0 \pm 3.8$ & $0.81 \pm 0.07$ & $65.6 \pm 3.3$ & $1.01 \pm 0.09$ \\
\hline
\end{tabular}
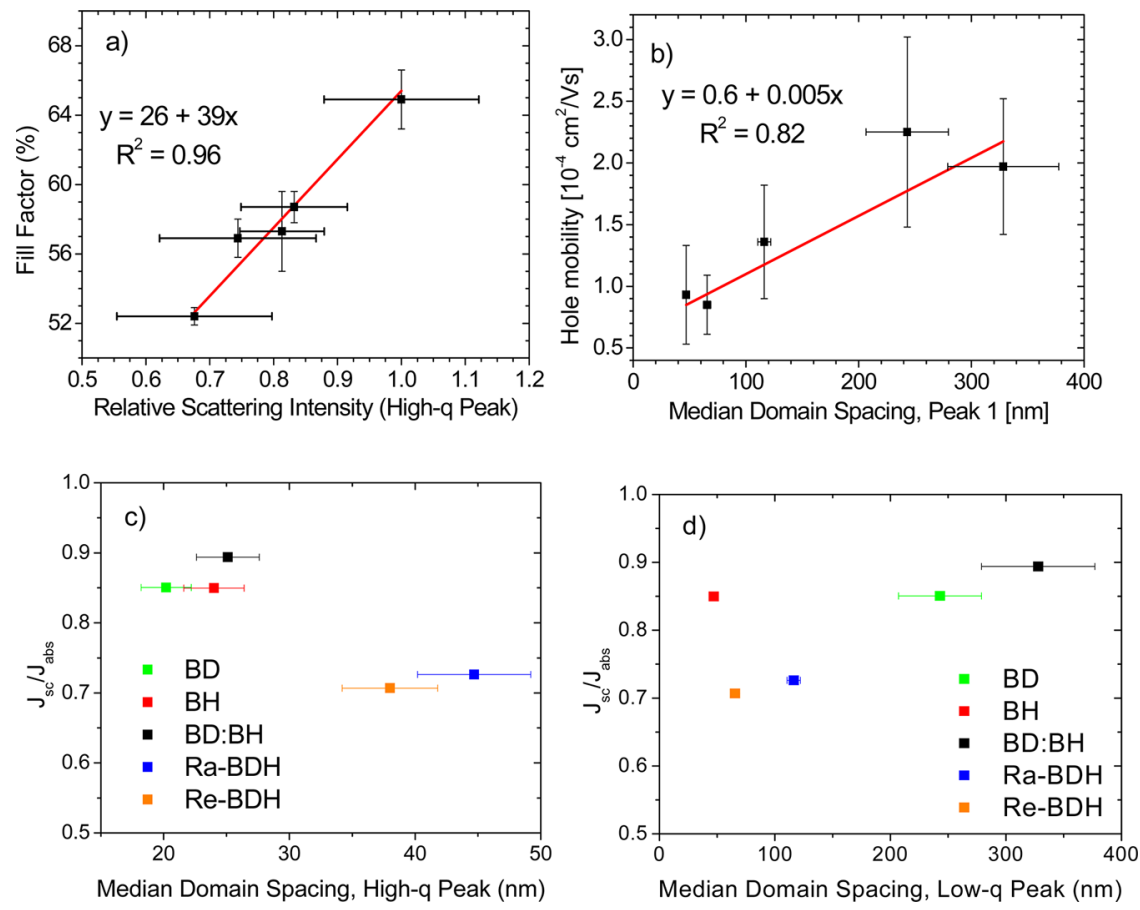

Figure 5. R-SoXS parameters, extracted from peak fitting analysis of R-SoXS sector averages, as correlated with device parameters.

pertinent results of the peak fitting analysis, namely median domain spacing and relative integrated scattering intensity.

In the studied systems, it appears that two domain spacing distributions (in a given blend) were formed during the device fabrication: a low- $q$ peak that corresponds to larger domains, and a high- $q$ peak that corresponds to the smaller domains (Table 3). Each peak type, as well as the sum of the peaks, was tested for possible correlation with the various photovoltaic performance metrics. Consider, first, the relative integrated scattering intensities of the small domains (i.e., high- $q$ peaks), which were normalized for thickness and material contrast effects. The material contrast between the polymers and PCBM was calculated using near-edge $\mathrm{X}$-ray absorption fine structure (NEXAFS) spectra $^{37}$ measured on beamline 5.3.2.2 at the Advanced Light Source. ${ }^{38,39}$ As shown in Figure 5a, this correlates strongly with the fill factor of the studied set of polymer BHJ devices. Such correlation has been previously observed $^{40}$ and reflects that the scattering intensity measures the combined impact of the domain purity and their volume fraction in a device, i.e., the average composition variations. ${ }^{41}$ More small domains or purer small domains can, up to a point, reduce the bimolecular recombination rate, thus improving the fill factor. ${ }^{42-45}$

Furthermore, the hole mobility correlates with the median domain spacing for those domains described by the low- $q$ peak (Figure $5 b$ ). We note that some domains described by this low$q$ peak have larger spacings than the film thickness, thus likely spanning the full width of the film and providing a direct path between electrodes, which could improve the mobility. Regarding the correlation of the normalized current, i.e., those aspects of $J_{\text {sc }}$ that are not related to difference in photon absorption, we note that the normalized current groups into two tightly scattered clusters, i.e., the two chemical blends $(0.71$ $\left.<J_{\mathrm{sc}} / J_{\mathrm{ab}}<0.73\right)$ and the other three devices $\left(0.85<J_{\mathrm{sc}} / J_{\mathrm{ab}}<\right.$ 0.89 ). Thus, no matter what physical parameter we extract from the morphology characterization, we will not observe any correlations to the normalized current, as shown in Figure 5, parts $\mathrm{c}$ and $\mathrm{d}$, where the normalized current was plotted against the median domain spacing of the low- $q$ and high- $q$ peak, respectively.

So the question remains: what would cause the reduced $J_{\mathrm{sc}}$ in these two terpolymer based solar cells? We assume that there is efficient and comparable exciton quenching, i.e., efficient charge transfer (CT) state formation. This assumption is by the PCBM miscibility with $\mathrm{BH}^{46}$ and low crystallinity of the polymers, which suggest they would be unlikely to form the large, pure domains necessary to prevent exciton quenching. The low polymer crystallinity, particularly $\pi-\pi$ stacking, has been observed in grazing-incidence wide-angle X-ray scattering (GIWAXS) experiments performed at beamline 7.3.3 at the Advanced Light Source; ${ }^{47}$ further details may be found in the Supporting Information. The lack of correlation of $J_{\mathrm{sc}} / J_{\mathrm{ab}}$ to any morphological parameters thus strongly implies that the differences in $J_{s c}$ would arise from differences in charge 
generation and geminate recombination. For instance, Burke and $\mathrm{McGehee}{ }^{48}$ recently argued that the short-range (i.e., terahertz) mobility controls charge generation, which offers one to account for the observed $J_{\text {sc }}$ differences in our series of polymers. In the two terpolymers based blends, the reduced aggregation, particularly of the $\mathrm{BD}$ units, evidenced in the UVvis spectra, leads to a degradation of local short-range mobility, which in turn reduces the charge generation and increases geminate recombination in the unaggregated segments of these two chemical blends.

\section{CONCLUSION}

In summary, we synthesized regularly alternating and random terpolymers from one donor unit and two different acceptor units. These two terpolymers were then compared to the parent $\mathrm{D}-\mathrm{A}$ polymers as well as to a physical blend of the parent polymers. Both terpolymers showed extended absorption compared to the parent polymers, but had different absorption coefficients than the physical blend. Most significantly, the terpolymers exhibited a significantly reduced aggregation signature. When normalized for optical effects, the random terpolymer had comparable photovoltaic performance with the regular terpolymer, but both fell short of the physical blend, largely due to a lower $J_{\mathrm{sc}}$ from these terpolymers based solar cells. This was surprising since in most previously literature reports, the regular terpolymer outperformed the random polymer in each comparative study. A study of the morphologies of the samples showed that the two binary blends, the physical ternary blend, and the two terpolymer blends all have fill factors of their individual solar cells correlating with the domain purity of the smaller domain, and hole mobility correlating with the median domain spacing of the larger domains. We hypothesize that the lack of aggregation leads to low local mobilities with a negative impact on charge generation and increases geminate recombination. Overall, this study demonstrates that certain design rules for terpolymers need to be achieved in order to harness their full potential to control morphology by synthetic means. For chemical blending to work, the material needs to have a molecular structure and overall architecture that will allow it to aggregate. Our work thus provides a useful guide for future synthesis and articulates a metric that can be easily checked by UV-vis spectroscopy.

\section{ASSOCIATED CONTENT}

\section{S Supporting Information}

The Supporting Information is available free of charge on the ACS Publications website at DOI: 10.1021/acs.macromol.5b02586.

General methods including CV measurements, solar cells fabrications and testing, SCLC hole mobility measurements, synthetic details for monomers and polymers, NMR spectra, R-SoXS measurement and data, and GIWAXS measurements and data (PDF)

\section{AUTHOR INFORMATION}

\section{Corresponding Author}

*E-mail: wyou@unc.edu (W.Y.).

\section{Author Contributions}

${ }^{\perp}$ Equal contribution

\section{Notes}

The authors declare no competing financial interest.

\section{ACKNOWLEDGMENTS}

We acknowledge Prof. Xiaoniu Yang and Dr. Xiaoli Zhao at Changchun Institute of Applied Chemistry, Chinese Academy of Sciences for GPC measurements, and UNC Department of Chemistry Mass Spectrometry Core Laboratory for Mass Spectrometry measurement. Q.Z, M.A.K., and W.Y. were supported by National Science Foundation (DMR-0954280, and DMR-1507249). X-ray characterization and analysis by A.H. and H.A. was supported by DOE, OS, BES, and MSE (DE-FG02-98ER45737).

\section{REFERENCES}

(1) Beaujuge, P. M.; Amb, C. M.; Reynolds, J. R. Spectral engineering in $\pi$-conjugated polymers with intramolecular donor- acceptor interactions. Acc. Chem. Res. 2010, 43 (11), 1396-1407.

(2) Kim, J. Y.; Lee, K.; Coates, N. E.; Moses, D.; Nguyen, T.-Q.; Dante, M.; Heeger, A. J. Efficient tandem polymer solar cells fabricated by all-solution processing. Science 2007, 317 (5835), 222-225.

(3) Kotlarski, J.; Blom, P. Ultimate performance of polymer: fullerene bulk heterojunction tandem solar cells. Appl. Phys. Lett. 2011, 98 (5), 053301.

(4) You, J.; Dou, L.; Hong, Z.; Li, G.; Yang, Y. Recent trends in polymer tandem solar cells research. Prog. Polym. Sci. 2013, 38 (12), 1909-1928.

(5) Wienk, M. M.; Kroon, J. M.; Verhees, W. J. H.; Knol, J.; Hummelen, J. C.; van Hal, P. A.; Janssen, R. A. J. Efficient Methano[70]fullerene/MDMO-PPV Bulk Heterojunction Photovoltaic Cells. Angew. Chem., Int. Ed. 2003, 42 (29), 3371-3375.

(6) Goubard, F.; Wantz, G. Ternary blends for polymer bulk heterojunction solar cells. Polym. Int. 2014, 63 (8), 1362-1367.

(7) Yang, L.; Yan, L.; You, W. Organic Solar Cells beyond One Pair of Donor-Acceptor: Ternary Blends and More. J. Phys. Chem. Lett. 2013, 4 (11), 1802-1810.

(8) Ameri, T.; Khoram, P.; Min, J.; Brabec, C. J. Organic ternary solar cells: a review. Adv. Mater. 2013, 25 (31), 4245-4266.

(9) Lu, L.; Kelly, M. A.; You, W.; Yu, L. Status and prospects for ternary organic photovoltaics. Nat. Photonics 2015, 9 (8), 491-500.

(10) Kang, T. E.; Kim, K.-H.; Kim, B. J. Design of terpolymers as electron donors for highly efficient polymer solar cells. J. Mater. Chem. A 2014, 2 (37), 15252.

(11) Rawson, J.; Stuart, A. C.; You, W.; Therien, M. J. Tailoring Porphyrin-Based Electron Accepting Materials for Organic Photovoltaics. J. Am. Chem. Soc. 2014, 136 (50), 17561-17569.

(12) Liu, Y.; Zhao, J.; Li, Z.; Mu, C.; Ma, W.; Hu, H.; Jiang, K.; Lin, H.; Ade, H.; Yan, H. Aggregation and morphology control enables multiple cases of high-efficiency polymer solar cells. Nat. Commun. 2014, 5, 5293.

(13) Price, S. C.; Stuart, A. C.; Yang, L.; Zhou, H.; You, W. Fluorine substituted conjugated polymer of medium band gap yields $7 \%$ efficiency in polymer-fullerene solar cells. J. Am. Chem. Soc. 2011, 133 (12), 4625-4231.

(14) Yang, Y.; Chen, W.; Dou, L.; Chang, W.-H.; Duan, H.-S.; Bob, B.; Li, G.; Yang, Y. High-performance multiple-donor bulk heterojunction solar cells. Nat. Photonics 2015, 9 (3), 190-198.

(15) Lu, L.; Xu, T.; Chen, W.; Landry, E. S.; Yu, L. Ternary blend polymer solar cells with enhanced power conversion efficiency. Nat. Photonics 2014, 8 (9), 716-722.

(16) Lu, L.; Chen, W.; Xu, T.; Yu, L. High-performance ternary blend polymer solar cells involving both energy transfer and hole relay processes. Nat. Commun. 2015, 6, 7327.

(17) Khlyabich, P. P.; Rudenko, A. E.; Street, R. A.; Thompson, B. C. Influence of polymer compatibility on the open-circuit voltage in ternary blend bulk heterojunction solar cells. ACS Appl. Mater. Interfaces 2014, 6 (13), 9913-9919.

(18) Ameri, T.; Khoram, P.; Heumüller, T.; Baran, D.; Machui, F.; Troeger, A.; Sgobba, V.; Guldi, D. M.; Halik, M.; Rathgeber, S.; Scherf, U.; Brabec, C. J. Morphology analysis of near IR sensitized polymer/ 
fullerene organic solar cells by implementing low bandgap heteroanalogue C-/Si-PCPDTBT. J. Mater. Chem. A 2014, 2 (45), 19461-19472.

(19) Kang, T. E.; Cho, H.-H.; Kim, H. j.; Lee, W.; Kang, H.; Kim, B. J. Importance of Optimal Composition in Random Terpolymer-Based Polymer Solar Cells. Macromolecules 2013, 46 (17), 6806-6813.

(20) Kim, J.-H.; Kim, H. U.; Kang, I.-N.; Lee, S. K.; Moon, S.-J.; Shin, W. S.; Hwang, D.-H. Incorporation of Pyrene Units to Improve Hole Mobility in Conjugated Polymers for Organic Solar Cells. Macromolecules 2012, 45 (21), 8628-8638.

(21) Li, H.; Liu, F.; Wang, X.; Gu, C.; Wang, P.; Fu, H. Diketopyrrolopyrrole-Thiophene-Benzothiadiazole Random Copolymers: An Effective Strategy To Adjust Thin-Film Crystallinity for Transistor and Photovoltaic Properties. Macromolecules 2013, 46 (23), 9211-9219.

(22) Zhou, J.; Xie, S.; Amond, E. F.; Becker, M. L. Tuning Energy Levels of Low Bandgap Semi-Random Two Acceptor Copolymers. Macromolecules 2013, 46 (9), 3391-3394.

(23) Wong, W. W.; Subbiah, J.; Puniredd, S. R.; Pisula, W.; Jones, D. J.; Holmes, A. B. Benzotriazole-based donor-acceptor conjugated polymers with a broad absorption in the visible range. Polym. Chem. 2014, 5 (4), 1258-1263.

(24) Hendriks, K. H.; Heintges, G. H.; Gevaerts, V. S.; Wienk, M. M.; Janssen, R. A. High-molecular-weight regular alternating diketopyrrolopyrrole-based terpolymers for efficient organic solar cells. Angew. Chem., Int. Ed. 2013, 52 (32), 8341-8344.

(25) Qin, T.; Zajaczkowski, W.; Pisula, W.; Baumgarten, M.; Chen, M.; Gao, M.; Wilson, G.; Easton, C. D.; Mullen, K.; Watkins, S. E. Tailored donor-acceptor polymers with an A-D1-A-D2 structure: controlling intermolecular interactions to enable enhanced polymer photovoltaic devices. J. Am. Chem. Soc. 2014, 136 (16), 6049-6055.

(26) Sun, W.; Ma, Z.; Dang, D.; Zhu, W.; Andersson, M. R.; Zhang, F.; Wang, E. An alternating D-A1-D-A2 copolymer containing two electron-deficient moieties for efficient polymer solar cells. J. Mater. Chem. A 2013, 1 (37), 11141.

(27) Wang, M.; Wang, H.; Yokoyama, T.; Liu, X.; Huang, Y.; Zhang, Y.; Nguyen, T. Q.; Aramaki, S.; Bazan, G. C. High open circuit voltage in regioregular narrow band gap polymer solar cells. J. Am. Chem. Soc. 2014, 136 (36), 12576-12579.

(28) Braunecker, W. A.; Oosterhout, S. D.; Owczarczyk, Z. R.; Kopidakis, N.; Ratcliff, E. L.; Ginley, D. S.; Olson, D. C. Semi-random vs Well-Defined Alternating Donor-Acceptor Copolymers. ACS Macro Lett. 2014, 3 (7), 622-627.

(29) Hendriks, K. H.; Heintges, G. H.; Wienk, M. M.; Janssen, R. A. Comparing random and regular diketopyrrolopyrrole-bithiophenethienopyrrolodione terpolymers for organic photovoltaics. J. Mater. Chem. A 2014, 2 (42), 17899-17905.

(30) Lim, Y.; Ihn, S.-G.; Bulliard, X.; Yun, S.; Chung, Y.; Kim, Y.; Chang, H.; Choi, Y. S. Controlling band gap and hole mobility of photovoltaic donor polymers with terpolymer system. Polymer 2012, 53 (23), 5275-5284.

(31) Khlyabich, P. P.; Rudenko, A. E.; Burkhart, B.; Thompson, B. C. Contrasting performance of donor-acceptor copolymer pairs in ternary blend solar cells and two-acceptor copolymers in binary blend solar cells. ACS Appl. Mater. Interfaces 2015, 7 (4), 2322-2330.

(32) Yang, L.; Zhou, H.; Price, S. C.; You, W. Parallel-like bulk heterojunction polymer solar cells. J. Am. Chem. Soc. 2012, 134 (12), $5432-5435$.

(33) Zhuang, W.; Bolognesi, M.; Seri, M.; Henriksson, P.; Gedefaw, D.; Kroon, R.; Jarvid, M.; Lundin, A.; Wang, E.; Muccini, M.; Andersson, M. R. Influence of Incorporating Different Electron-Rich Thiophene-Based Units on the Photovoltaic Properties of IsoindigoBased Conjugated Polymers: An Experimental and DFT Study. Macromolecules 2013, 46 (21), 8488-8499.

(34) Zhou, H.; Yang, L.; Stuart, A. C.; Price, S. C.; Liu, S.; You, W. Development of fluorinated benzothiadiazole as a structural unit for a polymer solar cell of 7\% efficiency. Angew. Chem., Int. Ed. 2011, 50 (13), 2995-2998.
(35) Gann, E.; Young, A. T.; Collins, B. A.; Yan, H.; Nasiatka, J.; Padmore, H. A.; Ade, H.; Hexemer, A.; Wang, C. Soft x-ray scattering facility at the Advanced Light Source with real-time data processing and analysis. Rev. Sci. Instrum. 2012, 83 (4), 045110.

(36) Ilavsky, J. Nika: software for two-dimensional data reduction. J. Appl. Crystallogr. 2012, 45, 324-328.

(37) Carpenter, J. H.; Hunt, A.; Ade, H. Characterizing morphology in organic systems with resonant soft X-ray scattering. J. Electron Spectrosc. Relat. Phenom. 2015, 200, 2-14.

(38) Warwick, T.; Ade, H.; Kilcoyne, D.; Kritscher, M.; Tylisczcak, T.; Fakra, S.; Hitchcock, A.; Hitchcock, P.; Padmore, H. A new bendmagnet beamline for scanning transmission $\mathrm{X}$-ray microscopy at the Advanced Light Source. J. Synchrotron Radiat. 2002, 9 (4), 254-257.

(39) Kilcoyne, A. L. D.; Tyliszczak, T.; Steele, W. F.; Fakra, S.; Hitchcock, P.; Franck, K.; Anderson, E.; Harteneck, B.; Rightor, E. G.; Mitchell, G. E.; Hitchcock, A. P.; Yang, L.; Warwick, T.; Ade, H. Interferometer-controlled scanning transmission X-ray microscopes at the Advanced Light Source. J. Synchrotron Radiat. 2003, 10 (2), 125136.

(40) Mukherjee, S.; Proctor, C. M.; Bazan, G. C.; Nguyen, T.-Q.; Ade, H. Significance of Average Domain Purity and Mixed Domains on the Photovoltaic Performance of High-Efficiency SolutionProcessed Small-Molecule BHJ Solar Cells. Adv. Energy Mater. 2015, 5 (21), 1500877.

(41) Collins, B. A.; Cochran, J. E.; Yan, H.; Gann, E.; Hub, C.; Fink, R.; Wang, C.; Schuettfort, T.; McNeill, C. R.; Chabinyc, M. L.; Ade, H. Polarized X-ray scattering reveals non-crystalline orientational ordering in organic films. Nat. Mater. 2012, 11 (6), 536-543.

(42) Ma, W.; Tumbleston, J. R.; Wang, M.; Gann, E.; Huang, F.; Ade, H. Domain Purity, Miscibility, and Molecular Orientation at Donor/ Acceptor Interfaces in High Performance Organic Solar Cells: Paths to Further Improvement. Adv. Energy Mater. 2013, 3 (7), 864-872.

(43) Ma, W.; Tumbleston, J. R.; Ye, L.; Wang, C.; Hou, J.; Ade, H. Quantification of nano- and mesoscale phase separation and relation to donor and acceptor quantum efficiency, J(sc), and FF in polymer:fullerene solar cells. Adv. Mater. 2014, 26 (25), 4234-4241.

(44) Li, W.; Albrecht, S.; Yang, L.; Roland, S.; Tumbleston, J. R.; McAfee, T.; Yan, L.; Kelly, M. A.; Ade, H.; Neher, D.; You, W. Mobility-Controlled Performance of Thick Solar Cells Based on Fluorinated Copolymers. J. Am. Chem. Soc. 2014, 136 (44), 1556615576.

(45) Stuart, A. C.; Tumbleston, J. R.; Zhou, H.; Li, W.; Liu, S.; Ade, H.; You, W. Fluorine Substituents Reduce Charge Recombination and Drive Structure and Morphology Development in Polymer Solar Cells. J. Am. Chem. Soc. 2013, 135 (5), 1806-1815.

(46) Li, W.; Yang, L.; Tumbleston, J. R.; Yan, L.; Ade, H.; You, W. Controlling Molecular Weight of a High Efficiency Donor-Acceptor Conjugated Polymer and Understanding Its Significant Impact on Photovoltaic Properties. Adv. Mater. 2014, 26 (26), 4456-4462.

(47) Hexemer, A.; Bras, W.; Glossinger, J.; Schaible, E.; Gann, E.; Kirian, R.; MacDowell, A.; Church, M.; Rude, B.; Padmore, H. A SAXS/WAXS/GISAXS Beamline with Multilayer Monochromator. J. Phys. Conf Ser. 2010, 247 (1), 012007.

(48) Burke, T. M.; McGehee, M. D. How High Local Charge Carrier Mobility and an Energy Cascade in a Three-Phase Bulk Heterojunction Enable > 90\% Quantum Efficiency. Adv. Mater. 2014, 26 (12), 1923-1928. 